\title{
Bhatara Banuwka (Sebutan Anumerta Raja Udayana)
}

\author{
I Wayan Wardha
}

Keywords: Bali, kings, kingdom, Hindu, grave

\section{How to Cite:}

Wardha, I. W. Bhatara Banuwka (Sebutan Anumerta Raja Udayana). Berkala Arkeologi, 14(2), 52-55. https://doi.org/10.30883/jba.v14i2.643

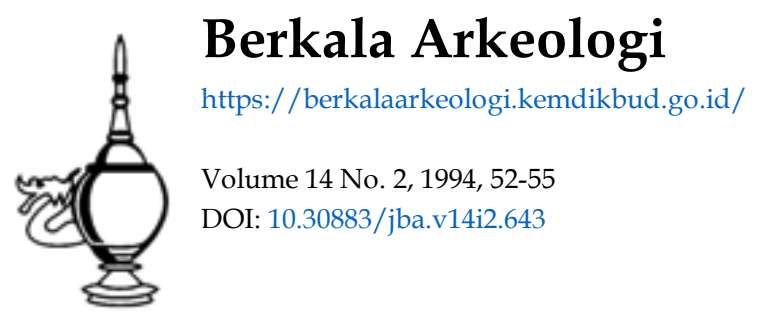

\section{@(@) $\Theta(\odot$}

This work is licensed under a Creative Commons Attribution-NonCommercial-ShareAlike $\underline{4.0 \text { International License. }}$ 


\title{
BHATARA BAÑUWKA \\ (Sebutan Anumerta Raja Udayana)
}

\author{
I Wayan Wardha \\ (Jurusan Arkeologi FS-UNUD)
}

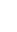

Daiam perjalanan sejarah Balı kuna yang Derlangsung hampır tujuh abad telah terjadı duapulun satu kall pergantian tampuk pımpinan dalam pemerıntahan. Semua raja-raja tersebut tidak semuanya dapat diketahus tempat persemayamannya Beberapa prasastı memberi petunjuk bahwa setelah wafat seorang raja dibuatkan can-di sebagal tempat pesemayamannya yang disebut oedharman. Misalnya, raja Ugrasena setelah warat di-dharma-kan di Air Madatu; raja Gunapriyadharmapatnı di-dharma-kan di Burwan, raja Udayana dı-dharma-kan di Bañuwka, Marakata dı Camara Anakwungsu di Jalu, dan Jayapangus di. oharma-kan dı Dharmahanyar

Beberapa prasasti lainnya juga menyebut iumah-nya seorang raja yang setelah wafat diseout bhatara (lakı-lakı) / bhatari (wanita). Sayangnya, sumber itu tidak menyebut secara langsung nama sang raja semasa hidupnya. Dapat disebutkan di sin! bhatara lumah di Banüpalasa ohatara lumah di Bwahrangga, bhatara lümah di Vusaawa, dl Candrımanık, di Guha.

Dugaan ıokasi (tempat) raja-raja itu di-dharma-kan akan dapat diketahur sepanjang tem-pat (toponımi; itu masih sama namanya sampal sekarang dan didukung dengan peninggalan arkeoogıs etapı tıdak demıkıan hainya dengan tempat di-dharma-kannya raja Udayana yang bernama Bañuwka. Toponım Bañuwka, sampai sekarang masih menjadı perbedaan pendapat para sarjana Berangkat dari hal tersebut dapat diimplikasıkan sejumlah pertanyaan.

Apakan Bar̃uwka itu nama tempat?

- Sagaimana bentuk bangunan sucınya?

Bıla permasalahan ını dapat dijawab, sudah tentu akan sangat berguna untuk pengembangan bidany arkeologı, khususnya dalam hal mengınterpretasıkan data

D. dalam usaha menelusuri Bañuwka ını, dıgunakan data prasasti sebagal sumber prımer sedangkan kıtab-kitab kesusasteraan (Negarakrtagama dan Pararaton) dan tradisı yang masih hidup di Bali digunakan sebagaı data sekunder yang bersifat peneguh atau pikukuh Sesuai dengan permasalahan yang ingın dıkajı, data primer didentıfikası dan diklasifikasıkan. Selanjutnya data prımer tersebut diasumsıkan dan diujı berdasarkan data sekunder Tulısan inı menggunakan metode deskrıptif dan korelasıonal guna mem- peroleh Jawaban terhadap permasalahan yang ingin dikaji

\author{
II
}

Sejak masa prasejarah, nenekmoyang bangsa Indonesıa telah mengenal suatu kebudayaan yang cukup tinggı Pada masa itu telan $\mathrm{d}_{\text {- }}$ kenal cara-cara penguburan mayat, balk tanpa wadah maupun dengan wadah seperti sarkofagus dan tempayan yang disertai bekal kubui Temuan bekal kubur dalam teknik penguburan tersebut memberi dugaan kuat bahwa kehıdupan ini akan berlangsung terus. Selain itu dalam pemujaan leluhur, mereka mempunyal kebıasaan mendirikan bangunan-bangunan berbentuk teras piramıd di lereng atau puncak bukıt dan pegunungan. Hal tersebut karena mereka percaya bahwa lereng bukit atau puncak gunung merupakan alam arwah.

Kepercayaan pada dunıa arwah tersebu: pada Jaman Indonesia Hindu masih berlanjut dan semakin berkembang. Mereka beranggapan ie. reng bukit, puncak gunung, dan pertemuan sungai, merupakan tempat para dewa. Tempat-tempat tersebut kemudian didirikan bangunan-bangunan sucı. Tradisı ını memberı petunjuk banwa pada masa itu telah terjadı pergeseran nılaı kepercayaan yang semula terkonsentrası pada pemujaan roh leluhur, berkembang menjadı kepercayaan terhadap adanya dewa. Dengan kata laın, pada Jaman indonesıa Hındu kepercayaan terhadap pemujaan leluhur menunggal dengan kepercayaan terhadap pemujaan para Dewa

Di Indonesia pada umumnya dan di Bali khususnya, pada masa sekarang ını pemujaar. terhadap leluhur dan pemujaan terhadap para aewa, dilakukan dalam satu tempat. Hal tersebut sehubungan dengan aktivitas yang runtut yastu setelah melaksanakan yadnya sraddha idl Bail disebut dengan yadnya memukur. malıgya nye$k a h)$, roh suci leluhur itu dianggap menunggat dengan dewa' Landasan yang mendasarı pelaksanaan upacara sepertı disinggung di atas, Japat dıperoleh dari kıtab Nagarakertagama, kıtab Pararaton, lontar Ligya dan tradisı yang sekarang masin hidup di Bali.

Kesusasteraan Negarakertagama member gambaran yang cukup jelas, bagaımana yadnya

Istilah teknisnya disebut dewapitara yastu ron :elunur yang telah didewata-kan 
sraddha untuk Rajapatnı (Gayatrı) dilaksanakan oleh Hayam Wuruk pada bulan Bhadrapada tahun $1284 C$ yaitu 12 tahun setelah wafatnya Gayatri tahun 1272 C. Sebagai simbol àtrrianya dipergunakan puspasarıra (badan bunga)." Tiga harl sebelum bulan purnama yaitu pada tanggal 13 Bhadrapada diselenggarakan upacara penurunan atma (Gayatri) oleh Pendeta Siwa. Dengan doa pujaan pendeta Siwa, diharapkan atma tersebut ber-sthana (menempati) puspasarira (badan bunga). Tepat pada bulan purnama Bhadrapada diadakan upacara pemujaan oleh para pendeta Buddha yang kemudian diikuti pula dengan upacara persembahyangan bersama oleh keluarga raja Hayam Wuruk, para patih dan rajaraja yang bernaung di bawah panji-panji kerajaan Majapahit Upacara semacam ini, di Bali disebut ngajum sekah (pengajuman) di mana saat ini para keluarga melaksanakan persembahyangan bersama Setelah sekah (puspasarira) dibakar, upacara selanjutnya adalah nganyut sekah ke laut atau sungai. Setelah Sang Hyang Puspasarîra dihanyutkan (Sang Hyang Puspasarira çigra linarut) dengan upakara selengkapnya maka atma menunggal dengan unsur tertinggi (Paramatma). Penunggalan ıni berarti tercapainya moksa sebagai latar belakang tujuan pelaksanaan yadnya frraddha (memukur.maligya) itu. Sebagai kelanjutan darı pelaksanaan yadnya çraddha di kerajaan Majapahit itu, dibuatlah pedharman untuk Gayatri di Bhayalango yang bernama Wisesapura atau Prajñaparamitapuri, di mana arca Prajñaparamita sebagal arca perwujudan (arca pratıstha)nya digunakan sebagai nyasa (simbol) dan media persembahyangan. Tingkat upacara terakhır inı disebut Widhi wedana yaitu upacara ngelinggihang (men-sthana-kan) dewata atau bhatara

Tradisı pembuatan Pratistha (arca perwujudanj sepertı terbaca di dalam kakawin Negarakitagama, ruparupanya identık dengan pembuatan patung perwujudan nenek moyang pada jaman prase jarah yang merupakan tradisi asli Indonesia, sebelum masuknya Hinduisme. Kalau memang benar demikian, diduga upacara çraddha seperti dimaksud di dalam ivegarakeıtagama tersebut merupakan kelanjutan tradısi penyembahan leluhur di indonesia yang dalam perkembangan selanjutnya berakulturası dengan tradisı penyembahan dewa. Hal tersebut mengakibatkan munculnya tradisı baru yaltu pemujaan leluhur yang telah menjadi dewa yang disebut dewata atau bhatara dan bhatari. Misalnya, raja Kertarlagara setelah wafat di dalam Negarakertagama disebut bhatara lumah "I Siwa Buddha. Sedang kan Gunapriyadharmapatni dan Dharma Udayana

Puspasanra tertuat dari susunan bunga-bunga di Bali disebut sekar (sekah) setelah wafat dı dalam prasasti-prasasti Balı sering disebut: Sang siddha dewata lumah ring erwka (prasasti Batuan, saka 944); haji dewata sang lümah ring airwka sajalu strï (pasast! Tengkulak, 945 C)

Anakwungsu selama pemerintahannya telah menerbitkan tiga puluh satu prasasti, delapan belas prasasti di antaranya menyebut nama $\mathrm{Pa}$ duka Haji Anakwungçunıra kalih bhatäri sang lümah i burwan mwang bhatara dewata sang lümah ring bañuwka Pemakaian unsur nama $i$ burwan dan ring bañuwka tersebut, menarık untuk diungkap lebih lanjut yaitu untuk mencarı tempat (toponimi) yang bernama Buiwan dan Bañuwka Burwan merupakan nama desa dengan peninggalan berupa pura Kadharman banjar Kutrı dengan arca Durghämahesäsurämardhıni $\mathrm{Na}$ mun untuk nama Bañuwka tidak terdapat indikasi apapun.

Di dalam usahanya mencari candi Air Weka dan juga patung Udayana, Goris (1957.20-21) antara lain berkata

"Namun kami belum tahu, dimanakah letak candi Air Weka itu dan juga patung Udayana belum kami ketahui. merupakan bhatara siapakah? Adalah dua candi yang mungkın candı Udayana itu: candi yang ada di pertemuan sungal Kerobokan dengan sungai Pakrisan di sebelah utara desa Manukaya. Satu Candi lain terdapat di desa Tatiapi sebelah barat desa Pejeng Letak keduanya itu boleh dikatakan Air Weka"

Gora Sirikan (1956: 5) berpendapat

"Letaknya (candi Bañuwka) tıdak jauh dari desa Burwan atau dari Bukit Dharma. Bañu=arr. sungai: Wka=anak, kecil. Ini berarti bahwa baginda (Udayana) dijenasahkan/dicandikan pada tebing sebuah sungai. dimana terdapat sumber mata air. Di sebelah utara desa Tegallinggah yaitu di tebing sungai Pakrisan terdapat 2 buah cand kembar dan dekat di situ terdapat beberapa buah pancuran yang airnya dianggap suct Kemungkinan candi-candi itulah yang menjadi iempat penjenasahannya karena letaknya tıdak jauh darı desa Burwan dan Bukit Dharma. Tetapi di situ tidak ada tulisan sehingga sulit dipertanggungjawabkan. Candi ini diketahui oleh Dinas Purbakala tahun 1953 akibat tanah longsor"

M.M. Sukarto K.Atmodjo (1972:5) antara laın menulis sebagaı berıkut:

"Suaminya Dharmodayana dicandikan di Bañuwka tetapi lokasi tempat tersebut masih belum jelas. Ada perkiraan bahwa pura Yeh Mangening di sebelah barat-daya Tirtha Empul atau di sebelah Utara Gunung Kawi Tampaksiring mungkin

Pemakaian partikel er (air) sebagal unsur namia anumerta. seterusnya digunakan oler: puta bungsunya 
tempat percandian Udayana. Dugaan inı berdasarkan artı perkataan Bañuwka yang mirip dengan Yeh Mangening Bañu atau Yeh=air dan wka. oka. cening = anak. Di atas bangunan prasada Yeh Mangening sampal sekarang masih dapat dilihat sebuah lingga batu dan di bawah pura terdapat sumber arr yang jernih"

Usaha mencari tempat yang bernama Bañuwka itu masih terus ditelusuri. I Gusti Gde Ardana dı dalam Pidato Pengenalan Jabatan Guru Besar menuliskan (Ardana;1988:2) 'walaupun nama Bariuwka dan Burwan sering disebut-sebut pada masa pemerintahan Anakwungsu (971-999 C) sampaı sekarang belum diketahui dengan pasti letak Bañüwa itu".

I Ketut Setiawan (1991:108) mengusulkan agar lokası yang bernama Bañuwka itu hendaknya dicarı di Kabupaten Karangasem atau setıdak-tidaknya di sekitar desa-desa Bugbug. Tenganan dan desa Tumbu. Boleh jadi mungkın Bañuwka itu adalah pura Candi Dasa atau barangkalı raja Udayana dimakamkan di dua tempat yaitu di pura Yeh Mangening dan di pura Candi Dasa. Semua itu belum jelas.

\section{III}

Guna memahamı permasalahan ını, tıdak kurang darı 40 prasastı yang perlu kamı periksa, dl samping prasastiprasasti yang dikeluarkan oleh Gunapriyadharmapatnı bersama Dharma Udayana Warmadewa (10 prasasti) yang memerıntah saka 911-933. Sebagaimana telah kita sepakatı bersama bahwa Gunapriya wafat sekitar 923-929 C, sedangkan Udayana sendiri mangkat setelah tahun 933 Ç (Sartono Kartodirdjo, 1975). Setelah pemerıntahan kedua suami istri ini, pemerıntahan di Bahı dipegang oleh Çri Sang A jñadewi (prasastı Sembıran saka 938, dan bukan oleh Erlangga, putra sulung suamı istri itu yang seharusnya berhak mewarısı memegang tampuk pemerıntahan dı Balı. Darı prasastiprasasti yang dikeluarkannya. kami mengetahui bahwa Erlangga yang dirahırkan di Bali 922 C kemudian memerintah dı Jawa Timur 938-964 C. Dengan kata laın, Erlangga tidak pernah memerintah di Balı, mungkın sekalı bagında nyentana nyeburın di Jawa Timur sepertı yang pernah dialami oleh ayahnya (Wardha, 1992:9-14). Akibatnya, Erlangga tidak berhak mewarisı tahta kerajaan ayahnya di Bali dan sebagaı penggantı setelah pemerıntahan Cri Sang Ajnadewi ialah Marakata (944-947 C)) dan kemudian dilanjutkan oleh Anakwungçu (971- 999 C)

Darı kedua orang putra mahkota yang berhak mewarısı kerajaan bagında suami istri itu, sampai sekarang telah ditemukan tıdak kurang darı 36 prasastı. Darı jumlah ini, hanya 3 prasasti yang memberi sedikit gambaran mengenal sebu- tan anumerta kedua suamı istrı itu seteiah baginda mencapaı moksa Darı prasastı Batuan 944 C kita memperoleh petunjuk bahwa Udayana telah dewatä dan bertempat dı sorgaloka. Dikatakan demikian karena pada lembar lb.4 tertulis "pāduka haji sang sıddha dewatā lumah rıng er wka ıng er paku". Mungkın keterangan inı dapat dipergunakan sebagai petunjuk,bangunan suci tempat Iümah-nya Udayana terdapat di Er Paku (Jukut Paku?). Keterangan yang dapat kami pergunakan sebagai petunjuk bahwa baginda telah mencapai moksa dan bertempat di sorgaioka adalah prasasti Tengkulak 945 C Prasasti Inı dapat dipergunakan sebagaı petunjuk bahwa Marakata adalah putra Gunapriya bersama Udayana (Ib.6: "---an wka, hajl dewatä sang lümah rıng air wka sajalu stri"--) dan yang berhak menjadi ahlı waris (kerajaan)nya. Keterangan yang menjadi petunjuk ke arah ini terbaca pada lembar 2a.1:--. "prasıddha kumalilir ing kulit kakı, sınıwı ring deça banten"---. Selanjutnya, sebutan anumerta raja suamı ıstri itu terdapat pula pada lembar lb.3 :---"haji dewatā sang lumah rıng erwka sajalu strî'-.- dan pada lembar lb.5 terbaca. "kunang pwa katekan swarggastā haji dewatā sang lūmah rıng air wka sajalu strī, ya ta karananya tan pakmitan prasasti"--.

Selain dua prasasti yang dikeluarkan oleh Marakata seperti telah kamı tunjukkan di atas ını, terdapat pula sebuah prasasti yang dikefuarkan oleh Anakwungsu yaitu prasasti Serai saka 989 Di dalam prasastı inı, kita memperoleh pula sedikit keterangan bahwa Anakwungçu juga ahli warıs dari baginda suamı istrı yang atmanya telah menunggal dengan Para -tma, disebut bhatara Pada lembar 5b.3-6 prasastı Seral, saka 989 itu tarbaca: -.."sambhanda nı panambah (4) nikanang mabwatthajl rı buru i lbu ni paduka haji mituturaken pangraksayanya anugrahanıratıta prabhu, makadi anugrahan bhatara sajalu stri ya tika tan (5) kapısınggin tkapnıng nayaka tkeng caksu para caksu kunang pwan molih maprarthanamuja ri bhatara ikanang rggap buru sanayaka an pra-siddha atmantyan bhatara sira nga (6; lilir , kulit kakı alinggıh ring maniratna sınghasana sıniwi nıng sabalidwipa mandala"...

Makna yang dapat dipetik darı ketıga prasastı di atas ini yaitu: Marakata dan Anakwungsu keduanya adalah putra mahkota yang berhak menjadı ahlı waris mahkota kerajaan sebagaı pengganti dewatā atau bhatarā bañuwka. De watā atau bhatara Bañuwka dımaksud di sını tentulah roh suci Gunapriyadharmapatnı dengan Udayana yang setelah melaluı proses pensucian darı tıngkat upacara Sawa wedana - atmā wedana sampal dengan ngenteg linggih yang disebut upacara widhi wedana, dimana pada tingkat terakhir ini, dibuatkanlah bangunan, lengkap dengan media perwujudannya yang sewaktuwaktu dapat 
digunakan sebagai nyasa pemujaan. Dalam keadaan seperti itu maka roh suci itu lalu disebut bhatära yaitu bhatära Bañuwka.

Penggunaan unsur nama anumerta bhatära Bañuwka selanjutnya secara konsisten digunakan oleh Anakwungsu: Paduka Haji Anakwungsu nıra kälih bhatäri lümah i Burwan, Bhatära lümah I Bañuwka. Penggunaan unsur nama nira dan kalih di sini, tentulah ada maksud dan tujuannya seperti tersirat dari uraian di atas

Bila sebutan anumerta bhatära Bañuwka dapat kita sepakati, permasalahan yang muncul kepermukaan dan perlu ditelusuri jawabannya adalah: dimanakah tempat bangunan suci itu dan bagaimana bentuk bangunannya. Hal ini nampaknya semakin diperlukan sebagai tempat mereka mohon restu seperti pernah dialami masa lalu. Prasasti Tengkulak 945 \& hanya menyebut roh suci Gunapriya dan Udayana berada di sorgaloka (katkan swargastä haji dewatä) dan menempati singasana mani-kam(alinggih ring maniratna singhasana) seperti terbaca pada prasasti Serai, 989 Ç. Prasasti Tengkulak, 945 Ç lembar lb. 3 antara lain juga menyebut bahwa bangunan itu terdapat di wilayah sungai Pakrisan yang disebut pula dengan Amarawati (sanghyang katyagan ing pakrisan mangaran ring amarawati). Wilayah mandala (katyagan) sungai Pakrisan ini lebih ivas dari wilayah Pantibumi. Dikatakan demikian sebab di dalam prasasti Tengkulak E (tanpa angka tahun) pada lembar 6b.1-2 terbaca: -.."kunang yan hana katyagan ring thaninya (2) wenang ya tan pasaji sekar ring panti bumi, tan parabyaparan dening watek kuturan, tan kna padesi mwang pabharu, apan pinaka thaninira sanghyang mandala rıng amarawati"---.

Petikan bagian kalimat di atas ini memberi petunjuk bahwa mandala katyagan itu secara teritorial lebih luas dari wilayah thani (banjar?). Di wilayah thani terdapat bangunan suci Pantibumi yang wilayahnya lebih sempit dan pemujanya lebih sedikit dibanding Prasada katyagan yang wiiayannya lebıh luas dan dipuja oleh orang-orang sabali dwipa mandala

\section{KEPUSTAKAAN}

Ardana, I Gustı Gde, 1988. Udayana. Peranannya dalam sejarah Bali pada abad X. Pidato Pengukuhan Dalam Jabatan Guru Besar Tetap dalam IImu Sejarah Inaonesia Kuna Pada FS - Universitas Udayana

Ginarsa,Ktut, 1961. Prasasti Baru Raja Marakata Bahasa dan Budaya No.112. Tahun IX
Jakarta, Lembaga Bahasa dan Kesusasteraan Departemen $P$ dan $K$

Goris, R, 1957. Dinasti Warmadewa dan Dharmawangsa di Pulau Bals. Bahasa dan Budaya.Tahun $\vee$ No.3. Jakarta, Lembaga Bahasa dan Budaya FS - Universitas Indonesıa.

Juynboll.H.H. 1923. Oudjavaansch-Nederlandsche Woordenlijst Leiden N.V Boekhandel en Drukkerij.E.J.Brili.

Mardiwarsito, L. \& Harimurti Kridalaksana, 1979 Struktur Bahasa Jawa Kuna. Jakarta

Mardiwarsito,L.1981. Kamus Jawa Kuna-Indonesia. Ende-Flores. Nusa Indah-Percetakan Arnoldus

Padmapuspita, Kı.J. 1966 Pararaton Jogjakarta Taman Siswa.

Sartono Kartodirdjo dkk. 1975. Sejarah Nasional Indonesia. Jakarta. Depdikbud

Setiawan, I Ketut, 1991. Mencari Lokalisasi Bañuwka. Majalah Widya Pustaka. Th.VIII No.2. Denpasar, FS - Universitas Udayana

Slametmulyana, Prof.Dr. 1979. Nagarakertogama dan Tafsir Sejarahnya Jakarta Bhratara Karya Aksara

Wardha, I Wayan, 1989. Industri Pengerajin Jaman Udayana. Laporan Penelitian Denpasar, Universitas Udayana

Wardha, I Wayan,1992. Dampak Perkawinan Eksogami Dalam Sejarah Bali Kuna (Sebuah Studi Kasus). Orasi IImiah Dalam Rangka HUT, XXXIV \& BK XI FS . Universitas Udayana, Denpasar

Lontar Ligya. Koleksi Fak Sastra Unud. No. 680

Lontar Yamapurana Tattwa. Koleksı Fak Sastra Unud No.42 